\title{
OPTIMIZATION OF DONNAN DIALYSIS FOR ALUM RECOVERY USING BOX BEHNKEN DESIGN
}

\author{
Dennis Asante-Sackey ${ }^{1}$, Sudesh Rathilal $^{2}$, Emmanuel Kweinor Tetteh ${ }^{3}$, Lingam Pillay ${ }^{4}$
}

\begin{abstract}
Most potable water treatment plants use aluminium salts as coagulants. This generates a lot of treatment residue which consist of a high amount of aluminium in the residue matrix. Recovery of the alum-coagulant from the potable water treatment for reuse provides direct process and economic advantages. Donnan Dialysis is an ion exchange process that has a proven advantage in coagulant recovery. The commercial application of this process requires bench scale optimization before implementation. In this study, a response surface methodology is applied to the Donnan system. Incorporated with the BoxBehnken experimental matrix, the main and interactional effects of input variables for optimum alum recovery was determined. The Nafion 117 cation exchange membrane was used. Using experimental results, the quadratic statistical module generated was significant with a low P-value $(<0.001)$. The statistical prediction from experimental results shows that high recoveries of $85-96 \%$ can be achieved.
\end{abstract}

UDC Classification: 502/504; DOI: http://dx.doi.org/10.12955/cbup.v6.1286

Keywords: Alum recovery, Donnan dialysis, residuals, ion exchange

\section{Introduction}

Coagulation is an integral physico-chemical process mostly deployed in conventional or hybrid potable water and wastewater treatment for the removal of particulates, natural organic matter, microorganisms, inorganic ions and metal complexes as larger flocs for subsequent removal through a solid/liquid separation chain such as clarification, sedimentation and filtration (Jiang, 2015; Teh \& Wu, 2014). The wide use of mineral coagulants is cost effective for the removal of contaminants. Most of these treatment facilities use hydrolytic salts of aluminium and iron as coagulants due to their relatively low cost, market availability and easy storage with alum as a dominating coagulant (Niquette et al., 2004).

Potable water treatment (PWT) generates residue streams with enormous quantities produced during coagulation. Residues are defined by the type of primary coagulant used at the treatment plant. An estimated yearly average of 100,000 tons of residue is generated by a potable water treatment plant whilst a global estimated average of 10,000 tons per day is generated by treatment plants (Ahmad et al., 2016). Sustainable management strategies for residue produced have generated environmental pollution, health risks and economic impact concerns. The current management strategy, mainly, disposal into landfills, hydrics and sewages have been faced with stringent environmental regulations and limited disposal space (Łukasiewicz, 2016). As economic needs are increasing, disposal sites are competing with agricultural and other industrial needs. Furthermore, the residue management method exposes soil surface and underground water, to contamination through rain water runoff, leaching and infiltration. These occurrences results in the increased cost of disposal per volume per area of land (Babatunde \& Zhao, 2007).

The implementation of a recovery, recycle and reuse (3 R's) management strategy seems to be the surest alternative (Ahmad et al., 2016) to adhere to the century's vision of attaining a green process and environment. The advantages of recovery of coagulants includes the reduction in demand for commercial coagulants, reduction in disposal volume, meeting discharge standards and reducing disposal cost (Keeley et al., 2012; Petruzzelli et al., 2000). With alum as the mostly used coagulant, research has focused on recovery and reuse of alum residuals. In Al-residues, hydroxide of aluminium constitutes over $39-75 \%$ by weight of the total solids in the residue (Evuti \& Lawal, 2011; Prakash \& SenGupta, 2003).

Various treatment or recovery methods applied in water and wastewater treatment are to balance between process efficiency and cost. Existing recovery, treatment and purification methods namely, acidification, basification, chemical precipitation, ion exchange, pressure driven membrane processes,

\footnotetext{
${ }^{1}$ Faculty of Engineering and the Built Environment, Durban University of Technology, South Africa, ingsackey@gmail.com

${ }^{2}$ Faculty of Engineering and the Built Environment, Durban University of Technology, South Africa, rathilals@dut.ac.za

${ }^{3}$ Faculty of Engineering and the Built Environment, Durban University of Technology, South Africa, ektetteh34@gmail.com, corresponding author

${ }^{4}$ Faculty of Engineering, Stellenbosch University, South Africa, pillayvl@sun.ac.za
} 
etc. are faced with various limitations (Evuti \& Lawal, 2011; King et al., 1975; Masschelein et al., 1985; Domenico Petruzzelli, 1998; Ulmert \& Särner, 2005). Most of these limitations have been reviewed by Evuti \& Lawal (2011).

Donnan Dialysis is a simple, easy to operate and energy saving ion exchange process that involves the counter diffusion of ions across a semipermeable membrane to cause separation (Davis, 2000). The process is driven by a chemical potential difference. The technology is in the early stages of application into recovery of coagulants including applications in water and wastewater treatment. Prakash \& SenGupta (2003) achieved $>70 \%$ recovery under a single step process. A seemingly one factor at a time (OFAT) study of membrane type on aluminum recovery has been reported (Prakash et al., 2004). The results show that the homogenous Nafion 117 membrane has a higher $(80 \%)$ recovery than the heterogeneous Ionac 3470 membrane (25\%).

There is limited information on input factors that affects the process for coagulant recovery. To adapt Donnan dialysis for commercial applications, there is the need to understand the controlling factors for optimization. Optimization aids in obtaining the best conditions for high recovery. The use of the OFAT method skips interactional effects and the relationship between input and output variables during the study of multiple factors (Tettheh et al., 2017). The response surface method, using Box Behnken Design (BBD) helps to optimize the process and understand the input and output correlation based on three level factorial points.

This study seeks to study Donnan dialysis application and the optimization in recovery of aluminium from the potable water treatment residue (PWTR). The experiment is carried out using BBD to evaluate the effect and interactions of feed concentration, sweep concentration and feed flowrate.

\section{Materials and Methods}

Alum residue samples were obtained from the evaporation pond of a local water treatment plant in South Africa that uses alum as a coagulant. $20 \mathrm{~g}$ of solid samples were digested with $1 \mathrm{~L} 0.05-0.5 \mathrm{M} \mathrm{HCl}$, filtered, washed and diluted to $3 \mathrm{~L}$. The sweep vessel was filled with a $1 \mathrm{~L}$ varied concentration of $\mathrm{HCl}$. Samples of the feed solution before and during recovery runs was subjected to atomic absorption analyses using a PerkinElmer atomic absorption spectrometer (AAS). The recovery process was studied for 24hrs. The peristaltic pump used had a maximum flowrate of $6 \mathrm{ml} / \mathrm{sec}$.

A Nafion 117 commercial cation exchange membrane manufactured by DuPoint Inc. was acquired from Sigma-Aldrich. The method by Napoli et al. (2013) was adapted and modified for this study to enhance the removal of the impurities.

The removal rate of aluminium was calculated by using Equation (1):

$$
Y_{A l}(\%)=\frac{C_{o V_{o}-} C_{e} V_{e}}{C_{o} V_{e}} \times 100
$$

where $\mathrm{C}_{\mathrm{o}}$ and $\mathrm{C}_{\mathrm{e}}$ are the initial and equilibrium concentrations $(\mathrm{mg} / \mathrm{l})$ and $\mathrm{V}_{\mathrm{o}}$ and $\mathrm{V}_{\mathrm{e}}$ are volume of initial and volume at equilibrium concentrations respectively

Design of Experiment

Minitab ${ }^{\circledR}$ (version 18) was used to design the experiment, perform ANOVA and optimize the process. The BBD with 15 experiments for 3 factors was carried out at random conditions. The percentage recovery was the response and the RSM was used to evaluate the interactions among the factors of concern at three levels of low (-1), medium $(0)$ and high $(+1)$. The low and high extremes were $55-95 \%$ for feed flowrate $\left(\mathrm{X}_{1}\right), 300-700 \mathrm{mg} / \mathrm{l}$ for feed concentration $\left(\mathrm{X}_{2}\right)$ and $0.25-0.75 \mathrm{M}$ for sweep concentration $\left(\mathrm{X}_{3}\right)$.

\section{Results and Discussion}

The aluminium is recovered in the final solution or sweep compartment as aluminium chloride. The BBD was used to design the experimental runs for main and interactional effects of input variables (Table 1). The RSM was used to establish a statistical module and provide optimum operating conditions of high aluminium yield.

Analysis of Variance

The analysis of variance (ANOVA) is shown in Table 2 for a full quadratic interaction term. The quadratic interaction is the most predictive module with a high probability $(\mathrm{P}>0.10)$ associated with the lack of fit. The P > F was less than 0.05 and has the highest correlation coefficient values for the actual 
$\mathrm{R}^{2}$, adjusted $\mathrm{R}^{2}$, and predicted $\mathrm{R}^{2}$. The comparison of predicted values against actual recovery (Figure 1) indicates that the model predicted the experimental data accurately.

\begin{tabular}{|c|c|c|c|c|}
\hline \multicolumn{6}{|c|}{ Table 1: Box-Behnken experimental design and response yield } \\
\hline $\begin{array}{c}\text { Run } \\
\text { Order }\end{array}$ & $\begin{array}{c}\text { Feed flowrate } \\
(\mathbf{\%})\end{array}$ & $\begin{array}{c}\text { Feed } \\
\text { Concentration } \\
(\mathbf{m g} / \mathbf{l})\end{array}$ & $\begin{array}{c}\text { Sweep } \\
\text { Concentration } \\
(\mathbf{M})\end{array}$ & $\begin{array}{c}\text { Al } \\
\text { Recovery } \\
(\mathbf{\%})\end{array}$ \\
\hline 1 & 75 & 500 & 0.5 & 81.30 \\
\hline 2 & 95 & 500 & 0.75 & 74.80 \\
\hline 3 & 55 & 300 & 0.5 & 89.75 \\
\hline 4 & 55 & 700 & 0.25 & 51.40 \\
\hline 5 & 75 & 500 & 0.5 & 79.50 \\
\hline 6 & 55 & 500 & 0.25 & 84.50 \\
\hline 7 & 75 & 300 & 0.25 & 87.64 \\
\hline 8 & 95 & 500 & 0.25 & 74.52 \\
\hline 9 & 95 & 300 & 0.5 & 87.85 \\
\hline 10 & 55 & 700 & 0.5 & 60.12 \\
\hline 11 & 95 & 700 & 0.5 & 52.70 \\
\hline 12 & 55 & 500 & 0.75 & 83.00 \\
\hline 13 & 75 & 500 & 0.5 & 80.65 \\
\hline 14 & 75 & 300 & 0.75 & 84.52 \\
\hline 15 & 75 & 700 & 0.75 & 53.90 \\
\hline Source: Authors & \multicolumn{4}{|l}{} \\
\hline
\end{tabular}

\begin{tabular}{|c|c|c|c|c|c|}
\hline Source & DF & $\begin{array}{c}\text { Adj } \\
\text { SS }\end{array}$ & $\begin{array}{l}\text { Adj } \\
\text { MS }\end{array}$ & $\begin{array}{c}F \\
\text { Value }\end{array}$ & $\begin{array}{c}\text { P-Value } \\
(\mathbf{P}>\mathbf{F})\end{array}$ \\
\hline Model & 9 & 2588.19 & 287.58 & 119.23 & 0.00003 \\
\hline $\mathrm{X}_{1}$ & 1 & 94.53 & 94.53 & 39.19 & 0.00153 \\
\hline $\mathrm{X}_{2}$ & 1 & 2166.14 & 2166.14 & 898.07 & 0.00000 \\
\hline $\mathrm{X}_{3}$ & 1 & 0.42 & 0.42 & 0.18 & 0.69269 \\
\hline Square & 3 & 310.80 & 103.60 & 42.95 & 0.00054 \\
\hline$X_{1}^{2}$ & 1 & 3.55 & 3.55 & 1.47 & 0.27911 \\
\hline $\mathrm{X}_{2}^{2}$ & 1 & 289.79 & 289.79 & 120.15 & 0.00011 \\
\hline $\mathrm{X}_{3}^{2}$ & 1 & 18.84 & 18.84 & 7.81 & 0.03821 \\
\hline 2-Way Interaction & 3 & 16.31 & 5.44 & 2.25 & 0.19995 \\
\hline $\mathrm{X}_{1} * \mathrm{X}_{2}$ & 1 & 7.62 & 7.62 & 3.16 & 0.13569 \\
\hline $\mathrm{X}_{1} * \mathrm{X}_{3}$ & 1 & 0.79 & 0.79 & 0.33 & 0.59141 \\
\hline $\mathrm{X}_{2} * \mathrm{X}_{3}$ & 1 & 7.90 & 7.90 & 3.27 & 0.13018 \\
\hline Error & 5 & 12.06 & 2.41 & & \\
\hline Lack-of-Fit & 3 & 10.40 & 3.47 & 4.17 & 0.19938 \\
\hline Pure Error & 2 & 1.66 & 0.83 & & \\
\hline Total & 14 & 2600.25 & & & \\
\hline \multicolumn{6}{|c|}{ Model Summary } \\
\hline $\mathbf{S}$ & R-sq & R-sq(adj) & \multicolumn{3}{|c|}{ R-sq(pred) } \\
\hline 1.55306 & $99.54 \%$ & $98.70 \%$ & \multicolumn{3}{|c|}{$93.46 \%$} \\
\hline
\end{tabular}

From the recoveries obtained during the BBD experiments, a statistical module using multiple regression models was used to develop a regression equation (Equation 2) relating the impact levels of the factors to the recovery removal efficiency. The impact is established by the scaled coefficients to accommodate units of each factor.

$$
\begin{aligned}
Y_{\text {actual }}= & 81.8-0.412 X_{1}+0.1510 X_{2}+14.5 X_{3}+0.00245 X_{1}^{2}-0.000221 X_{2}^{2} \\
& -36.1 X_{3}^{2}-0.000345 X_{1} X_{2}+0.089 X_{1} X_{3}+0.0281 X_{2} X_{3}
\end{aligned}
$$




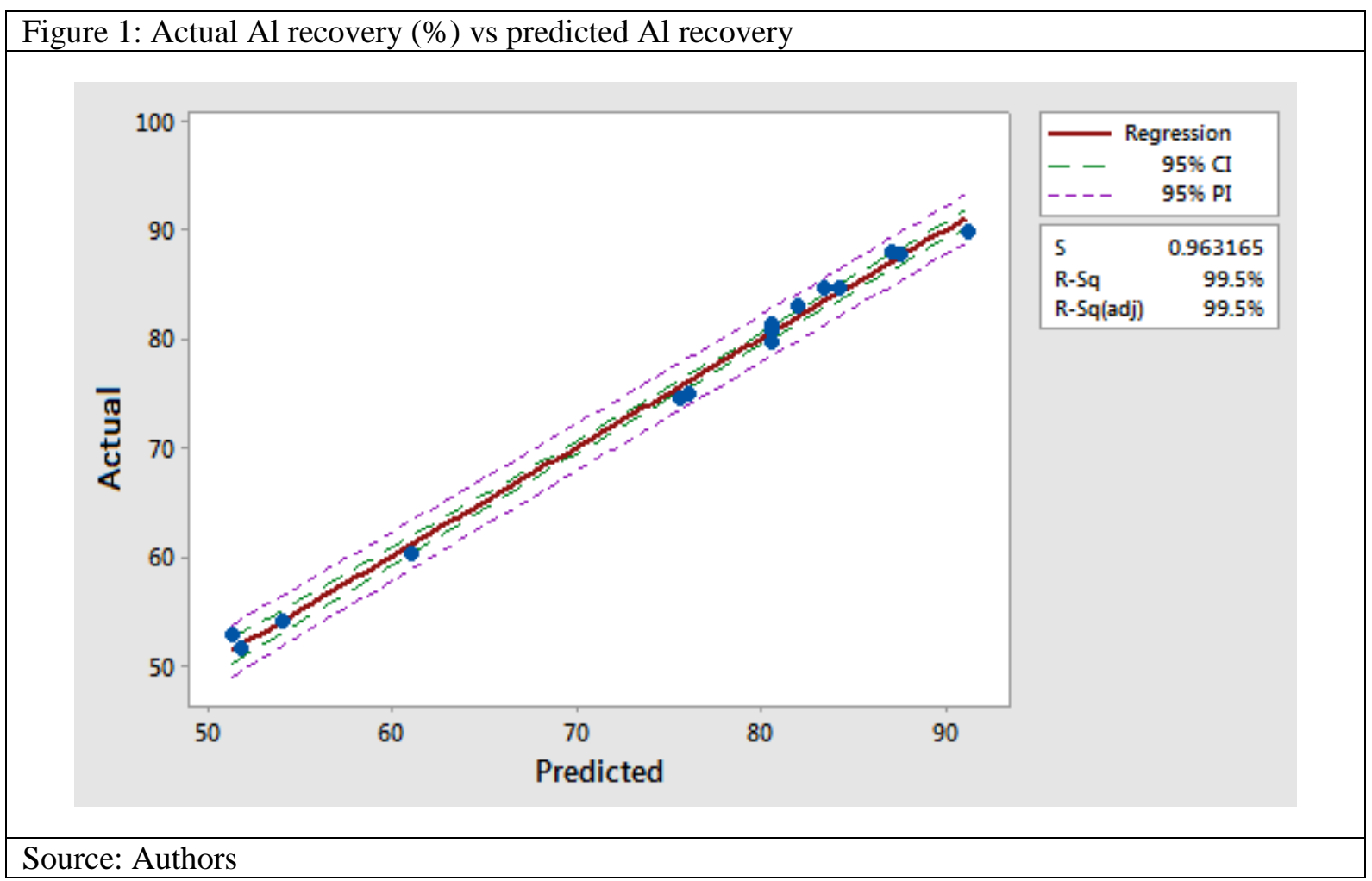

Optimization

The experimental data was studied on a contour response plot to evaluate the operational regions for higher performances of the DD system. Optimization was set to achieve target and maximum yields. From Figure 2, a target recovery range of $80-90 \%$ can be achieved when the feed concentration is between $300-550 \mathrm{mg} / \mathrm{L}$, feed flowrate of $55-95 \%$ and sweep concentration of $0.25-0.75 \mathrm{M}$. Observing the sweep concentration and feed flowrate, a feed flowrate of 55-68\% will still achieve the same recovery range. This reduces the chemical cost involved at the sweep phase. Furthermore, the sweep concentration and feed concentration interactions assist in identifying the feed concentration range to achieve a high recovery of $80-90 \%$. The observed feed concentration to be used is narrowed from $300-$ $550 \mathrm{mg} / \mathrm{l}$ to $300-470 \mathrm{mg} / \mathrm{l}$.

The effect of each factor on recovery is clearly demonstrated by the response surface plot (Figure 3) for their respective two-way interactions. It is observed in interactions that has feed concentration (A and $\mathrm{C})$, the recovery decreases at increasing feed concentrations. This effect is due to the high concentration gradient that arises at the solution-membrane interface causing concentration polarization (Baker, 2012). Furthermore, a high concentration of feed solution at high contact time increases the concentration polarization. In addition, a high flowrate reduces the rate of target ion across the membrane. This can be due to the small contact time that the feed solution has with the membrane surface. The limited contact time at high concentrations reduces the concentration profile at the feed section. This can lead to a rise in the osmotic effect (Baker, 2012).

Using a feed concentration range of 300-400 $\mathrm{mg} / \mathrm{l}$, feed flowrate $(50-60 \mathrm{mg} / \mathrm{l})$ and sweep concentration (0.2-0.4 M) will achieve a balance between the process limitations established by increasing flowrate and concentrations. At these experimental points, a high recovery (90-96\%) is attained.

\section{Conclusion}

The use of RSM coupled with BBD in this study illustrate clearly the impact of each factor and optimal conditions for high coagulant recovery. The use of BBD to develop the experimental run clearly establishes an interactional effect and provides a distribution point fully at the regions of interest. The RSM provided a 3D observation of the main and interactional effects. It has been established that at a lower concentration and a higher contact time, process limitation caused by concentration polarization and osmotic effect is not observed. 

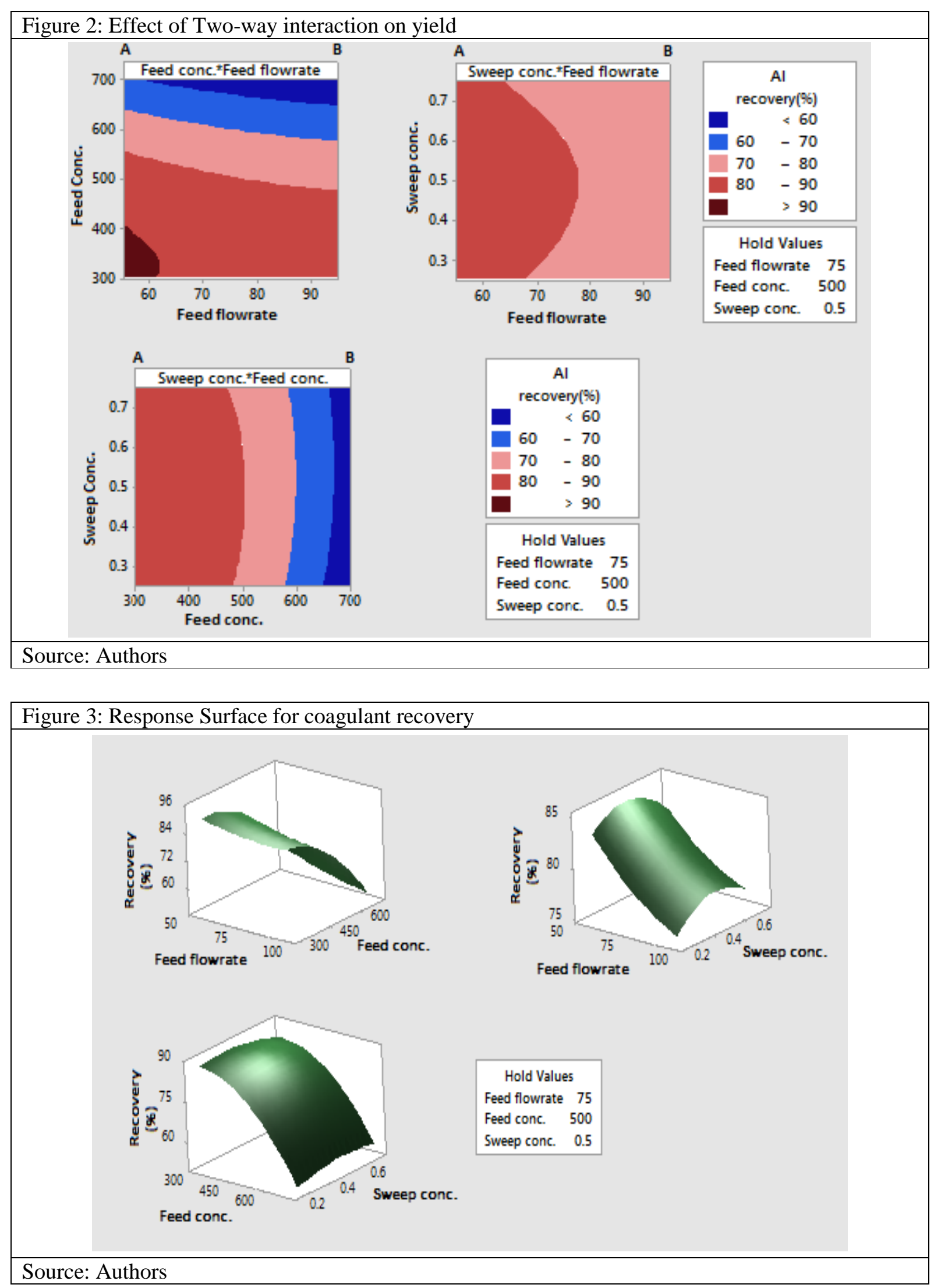

\section{Acknowledgements}

We wish to thank the South Africa Water Research Commission (WRC) for funding this research as well as the Durban University of Technology (DUT) for their support. 


\section{References}

Ahmad, T., Ahmad, K., \& Alam, M. (2016). Sustainable management of water treatment sludge through 3'R' concept. Journal of Cleaner Production, 124, 1-13. https://doi.org/10.1016/j.jclepro.2016.02.073

Babatunde, A. O., \& Zhao, Y. Q. (2007). Constructive Approaches Toward Water Treatment Works Sludge Management: An International Review of Beneficial Reuses. Critical Reviews in Environmental Science and Technology, 37(2), $129-164$. https://doi.org/10.1080/10643380600776239

Baker, R. W. (2012). Membrane Technology and Application. Membrane Technology (3rd ed.). West Sussex-UK: John Wiley \& Sons Ltd. Retrieved from http://linkinghub.elsevier.com/retrieve/pii/S0958211896901330

Davis, T. A. (2000). Donnan Dialysis. In Membrane Separations (Vol. 2, pp. 1701-1707). Annandale-NJ: Academic Press.

Evuti, A. M., \& Lawal, M. (2011). Recovery of coagulants from water works sludge : A review. Advances in Applied Science Research, 2(6), 410-417.

Jiang, J. Q. (2015, May). The role of coagulation in water treatment. Current Opinion in Chemical Engineering. https://doi.org/10.1016/j.coche.2015.01.008

Keeley, J., Jarvis, P., \& Judd, S. J. (2012). An economic assessment of coagulant recovery from water treatment residuals. Desalination, 287, 132-137. https://doi.org/10.1016/j.desal.2011.09.013

King, P. H., Chen, B. H. H. C., \& Weeks, Jr., R. K. (1975). Recovery and Reuse of Coagulants from Treatment of Water and Wastewater. Virginia Water Resources Research Center, (77), 15782. Retrieved from https://vtechworks.lib.vt.edu/bitstream/handle/10919/25734/WRRC_Bull_77.pdf?sequence=1

Łukasiewicz, E. (2016). Post-coagulation sludge management for water and wastewater treatment with focus on limiting its impact on the environment. Economic and Environmental Studies, 16(4), 831-841. Retrieved from www.ees.uni.opole.pl

Masschelein, W. J., Devleminck, R., \& Genot, J. (1985). The feasibility of coagulant recycling by alkaline reaction of aluminium hydroxide sludges. Water Research, 19(11), 1363-1368. https://doi.org/10.1016/0043-1354(85)90302-1

Napoli, L., Lavorante, M. J., Franco, J., Sanguinetti, A., \& Fasoli, H. (2013). Effects on nafion ${ }^{\circledR} 117$ membrane using different strong acids in various concentrations. Journal of New Materials for Electrochemical Systems, 16(3), 151-156. https://doi.org/10.14447/jnmes.v16i3.4

Niquette, P., Monette, F., Azzouz, A., \& Hausler, R. (2004). Impacts of substituting aluminum-based coagulants in drinking water treatment. Water Quality Research Journal of Canada, 39(3), 303-310. Retrieved from http://citeseerx.ist.psu.edu/viewdoc/download?doi=10.1.1.575.8197\&rep=rep1\&type=pdf

Petruzzelli, D. (1998). Aluminum recovery from water clarifier sludges by ion exchangeComparison of strong and weak electrolyte cation resins performances. Reactive and Functional Polymers, 38(2-3), 227-236. https://doi.org/10.1016/S13815148(97)00155-7

Petruzzelli, D., Volpe, A., Limoni, N., \& Passino, R. (2000). Coagulants removal and recovery from water clarifier sludge. Water Research, 34(7), 2177-2182. https://doi.org/10.1016/S0043-1354(99)00357-7

Prakash, P., Hoskins, D., \& SenGupta, A. K. (2004). Application of homogeneous and heterogeneous cation-exchange membranes in coagulant recovery from water treatment plant residuals using Donnan membrane process. Journal of Membrane Science, 237(1-2), 131-144. https://doi.org/10.1016/j.memsci.2004.03.016

Prakash, P., \& SenGupta, A. K. (2003). Selective Coagulant Recovery from Water Treatment Plant Residuals Using Donnan Membrane Process. Environmental Science \& Technology, 37(19), 4468-4474. https://doi.org/10.1021/es030371q

Teh, C. Y., \& Wu, T. Y. (2014). The potential use of natural coagulants and flocculants in the treatment of urban waters. In J. . Yong, P. Y. Liew, J. J. Klemes, \& P. S. Varbanov (Eds.), Chemical Engineering Transactions (pp. 1603-1608). Prague: AIDIC: Italian Association of Chemical Engineering. https://doi.org/10.3303/CET1439268

Tettheh, E. K., Rathilal, S., \& Chollom, M. N. (2017). Pre-treatment of industrial mineral oil wastewater using response surface methodology. In WIT Transactions on Ecology and The Environment (Vol. 216, pp. 181-191). WIT Press. https://doi.org/10.2495/WS170171

Ulmert, H., \& Särner, E. (2005). The ReAl Process - A combined membrane and precipitation process for recovery of Aluminum from waterwork sludge. Vatten, 61, 273-281. Retrieved from http://www.tidskriftenvatten.se/wpcontent/uploads/2017/04/48_article_2376.pdf 